\title{
Estimating Combined Health Risks of Nanomaterials and Antibiotics From Natural Water: a Proposed Framework
}

Minashree Kumari ( $\nabla$ minashreekumari2501@gmail.com )

IIT (ISM) Dhanbad

Arun Kumar

IIT Delhi: Indian Institute of Technology Delhi

\section{Research Article}

Keywords: Antibiotics, nanoparticles, interaction, water, health risk, oral exposure

Posted Date: June 9th, 2021

DOl: https://doi.org/10.21203/rs.3.rs-541720/v1

License: (c) (1) This work is licensed under a Creative Commons Attribution 4.0 International License.

Read Full License

Version of Record: A version of this preprint was published at Environmental Science and Pollution Research on October 1st, 2021. See the published version at https://doi.org/10.1007/s11356-021-16795$\mathrm{x}$. 
1 Estimating combined health risks of nanoparticles and antibiotics from natural water:

2 A proposed framework

3

Minashree Kumari $^{1 *}$ and Arun Kumar ${ }^{1}$

$4 \quad{ }^{1 *}$ Post-Doctoral Fellow, Environment Engineering Section, Department of Civil Engineering,

5 Indian Institute of Technology Delhi, Hauz Khas, Delhi-110017, Email:

6 minashreekumari2501@ gmail.com, +91-11-2659-1166; Fax: (+91)-11-2658-1117

$7{ }^{1}$ Associate Professor, Environment Engineering Section, Department of Civil Engineering,

8 Indian Institute of Technology Delhi, Hauz Khas, Delhi-110017, Email:

$9 \quad$ arunku@ civil.iit.ac.in.

10

11

12 Abbreviations

13

ABs antibiotics

$14 \quad \mathrm{ADD}$

average daily dose

15 ATSDR

Agency for Toxic Substances and Disease Registry

16 BAF

bio-accessibility fraction

17 CDI

chronic daily intake

$18 \mathrm{CuO}$

copper oxide

$19 \quad \mathrm{Fe}_{3} \mathrm{O}_{4}$

iron oxide

20 HQ

hazard quotient

21 IRIS

Integrated Risk Information System

22 NPs

nanoparticles

23 PNEC

Predicted No-Effect Concentration

$24 \quad$ RfD

reference dose

$25 \quad \mathrm{TiO}_{2}$

titanium dioxide 
zinc oxide

\section{$\underline{\text { Abstract }}$}

Nanoparticles are the major class of emerging contaminant detected at relatively high concentrations in aquatic environment. They are likely to co-exist with other chemical pollutants such as antibiotics in natural water systems. There are chances that if they are taken up orally, might pose adverse effects to human health. To address this issue, a risk framework is developed to study the combined exposure of nanoparticles and antibiotics in natural waters for the first time. The framework was applied to a hypothetical exposure of nanoparticles $\left(\mathrm{CuO}, \mathrm{ZnO}, \mathrm{Fe}_{3} \mathrm{O}_{4}\right.$ and $\left.\mathrm{TiO}_{2}\right)$ and antibiotics (ciprofloxacin, $\mathrm{CIP}$; ofloxacin, OFX; norfloxacin, NOR; levofloxacin, LEVO) to estimate human risks in a six-step approach for two different exposure scenarios i.e. availability adsorption isotherm data and vice versa. Risk was also estimated for the released fragments of antibiotics, nanoparticles and metal ions in the human digestive system. Mixture toxicity risk assessment was conducted for pairs (i) antibiotics and metal ions, (ii) antibiotics and nanoparticles, and (iii) nanoparticles and metals ions. Though the estimated risk values were observed to be less than 1 (both hazard quotients and hazard interactions less than 1) for all the conditions and assumptions made but it requires through monitoring of the studied contaminants in water to protect humans from

47 their adverse effects, if any. Maximum allowable concentrations at which no risk occurs to humans was found to be (maximum values): antibiotics (233.8 $\mu \mathrm{g} / \mathrm{L}, \mathrm{NOR})$; metal ions (1.02 $\times 10^{9} \mathrm{mg} / \mathrm{L}, \mathrm{Ti}^{2+}$ ions $)$, and nanoparticles $\left(6.68 \times 10^{5} \mathrm{mg} / \mathrm{L}, \mathrm{TiO}_{2}\right)$, respectively. 


\section{Introduction}

53

54

In the past few years, increased concerns have been raised due to occurrence of a wide variety of emerging contaminants including nanomaterials, pharmaceutical drugs etc., in natural water systems. Studies suggest that the concentration of these contaminants in water ranged from $\mu \mathrm{g} / \mathrm{L}$ to $\mathrm{ng} / \mathrm{L}$ (Chen et al., 2016; Ebele et al., 2017) and even high concentration values has also been reported. Nanoparticles usually display unique physical and chemical properties, and because of their inherent reactivity with other pollutants, nanoparticles may act as a carrier and co-occur with other pollutants producing long-term environmental and health risks (Azizi et al., 2016; Wang et al., 2016).

Upon release and emission, contaminants like nanoparticles may interact with chemicals (antibiotics) in the environment, potentially leading to a co-exposure of organisms and the occurrence of mixture effects (Naasz et al., 2018). That co-exposure to nanoparticles and antibiotics may occur is a valid assumption. Both substances are likely to be present and co-exist in the aquatic environment (Lammel et al., 2019). Although studies have been conducted to identify the occurrence of these contaminants but very little or restricted information is available about their environmental exposure (Coll et al., 2016; Holden et al., 2014). In real life scenarios, they might differ in their toxicity or can undergo transformation to produce products which under certain circumstances might show harmful effects and thus needs to be addressed.

Organisms are usually exposed to multiple mixtures of contaminants instead of single compounds (Uwizeyimana et al., 2017). During the process of passage, it is possible that nanoparticles or pharmaceutical drugs can form nanoparticle-toxin complexes or antibiotics 
complexes or even produce inter-category complexes of two contaminants due to nanoparticles high surface area and large aggregates (Zhu et al., 2011) thus, there are ongoing concerns on evaluating the environmental risk for the mixtures containing NPs. However, studies on the interaction of two different types of emerging contaminants have so far not been reported. In recent years the scientific community has undertaken enormous efforts to assess the eco-toxic potential of nanomaterial (Menard et al., 2011), but there are comparatively few studies that have investigated their interaction and combined toxicological effects with co-existing “traditional” environmental pollutants (Canesi et al., 2015; Hartmann and Baun, 2010; Naasz et al., 2018).

Looking into the potential adverse effects of these contaminants on human health, risk assessment studies have been conducted for some classes, for example, nanoparticles (Parsai and Kumar, 2020), pharmaceutical drugs (antibiotics) (Kumari and Kumar, 2020) etc., (Supplementary Table S1) but none of the reported studies (as per authors best knowledge) have tried to capture the interaction aspect linked with nanoparticles and antibiotics in natural water systems. Lack of available guidelines and regulations adds to the ongoing problem and makes it even more difficult, if not properly taken care of. Therefore, it becomes imperative to study and identify the interaction of these contaminants in water so that guideline values can be formulated for exercising appropriate control measures.

This study aimed at proposing a framework to determine the risk exposure effects of nanoparticles and antibiotics to the human digestive media or GI-tract followed by oral ingestion. Widely detected nanoparticles, NPs $\left(\mathrm{ZnO}, \mathrm{CuO}, \mathrm{Fe}_{3} \mathrm{O}_{4}\right.$, and $\left.\mathrm{TiO}_{2}\right)$ and pharmaceutical drugs, antibiotics (Ciprofloxacin, Ofloxacin, Norfloxacin, and Levofloxacin) in natural water were selected. 


\section{Methodology}

Figure 1 shows the flow diagram of the proposed framework for determining health risk estimates due to the interaction of nanoparticles and antibiotics in natural water followed by oral ingestion. The study used a six-step risk assessment approach to determine risk exposure effects of nanoparticles and antibiotics to human health (Kumari and Kumar, 2020a; Kumar et al., 2014). Briefly, this framework assumes that when these contaminants enters into the human body via oral route they might get disintegrate into respective antibiotics and nanoparticles with due course of time in the human digestive system. The released nanoparticles might get further dissolved into their respective ions, releasing free nanoparticles. These released metals can cause harmful health effects in spite of the fact that zinc, copper, and iron are essential elements for all living organisms if present in excessive quantities (Evangelou et al., 2007; Twining et al., 2005). Therefore, this approach assumes the probability of risk exposure effects due to released antibiotics and released nanoparticles in the human digestive system. Risk assessment study was also conducted for free nanoparticles and free metals ions after the dissolution of nanoparticles in human digestive liquid to check whether they pose any possible health risks or not. This study does not consider the size, shape, charge, and surface area of nanoparticles as they might show large variation after their dissolution in human digestive system as it is reasonably tough to capture these aspects in real life scenarios.

(1)


Dose-response (Step 3)

RfD for Nanoparticles

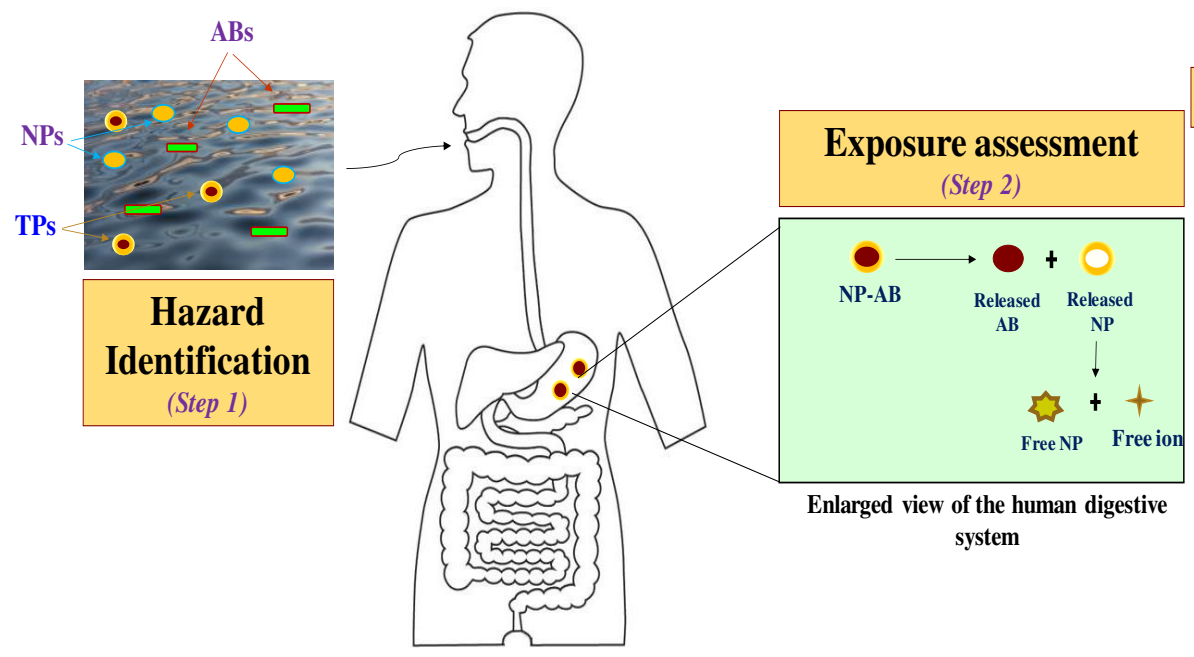

ADI for Antibiotics

Risk Estimation (Step 4)

Fig. 1 Hypothetical schematic diagram showing the uptake of nanoparticles-antibiotics transformed products and their dissolution in the human digestive system (NPs $=$ nanoparticles, $\mathrm{ABs}=$ antibiotics, TPs $=$ transformed products, $\mathrm{HQ}=$ hazard quotient, $\mathrm{EC}=$ Environmental concentration, $\mathrm{PNEC}=$ Predicted no-effect concentration; $\mathrm{RfD}=$ Reference dose $;$ ADI = Acceptable daily intake)

\subsection{Hazard Identification}

Hazard identification involves identifying the material of interest and collecting information

132 for which risk evaluation needs to be done. To determine the suitability of the suggested

133 framework, this study considered the hypothetical exposures of nanoparticles and antibiotics for illustrative purpose. Nanoparticles such as $\mathrm{CuO}, \mathrm{ZnO}, \mathrm{Fe}_{3} \mathrm{O}_{4}$ and $\mathrm{TiO}_{2}$ were considered as they are used as antimicrobial agents and additives in consumer and health-care products. The risk assessment of selected nanoparticles is essential as several research investigations have

137 shown their adverse effects to human health (Croteau et al., 2014; Ye et al., 2018). Amongst 138 the nanoparticles selected iron oxide nanoparticles $\left(\mathrm{Fe}_{3} \mathrm{O}_{4}, \gamma-\mathrm{Fe}_{2} \mathrm{O}_{3}\right.$ and superparamagnetic 
IONPs) have been extensively used for pharmaceutical applications (Ding \& Guo, 2013;

Namvar et al., 2014). CuO NPs might induce oxidative stress resulting in destruction of human liver cell (Shukla et al., 2013). $\mathrm{ZnO}$ is one of the most frequently detected NPs in surface water (Kurlanda-Witek et al., 2014) and has been reported be cytotoxic and harmful compared to other metallic nanoparticles (Li et al., 2020).

To study the interaction of nanoparticles with antibiotics, the most widely detected fluoroquinolones (FQs) antibiotics [ciprofloxacin (CIP), ofloxacin (OFX), norfloxacin (NOR), and levofloxacin (LEVO)] in the environmental media were selected owing to their use in the treating pulmonary, urinary, and digestive infections. The selected antibiotics are also effective in treating wide range of pathogenic bacteria (gram-negative and grampositive) and mycoplasmas (Hooper and Wolfson, 1993; MacGowan and Andersson, 2003). CIP, NOR, and OFX common antibiotics administered to humans (Alder et al. 2001; Choma Spiteller, 2007) and LEVO has been listed as one of the most essential medicine of human use by the World Health Organization (Hooper and Rubinstein, 2003). The environmentally occurring concentration (EC) of antibiotics and nanoparticles is taken from published scientific literature. The information is provided as supplementary text Table S2 and S3.

\subsection{Exposure assessment}

This research study evaluated health risks due to the exposure of inter category emerging contaminants (nanoparticles and antibiotics) to children as they have been recognised to be the most sensitive sub-population compared to adults (Preston, 2004). To determine exposure effects, health risks was estimated considering two different scenarios as mentioned above in

Fig. 1a. Detailed information is provided below. 


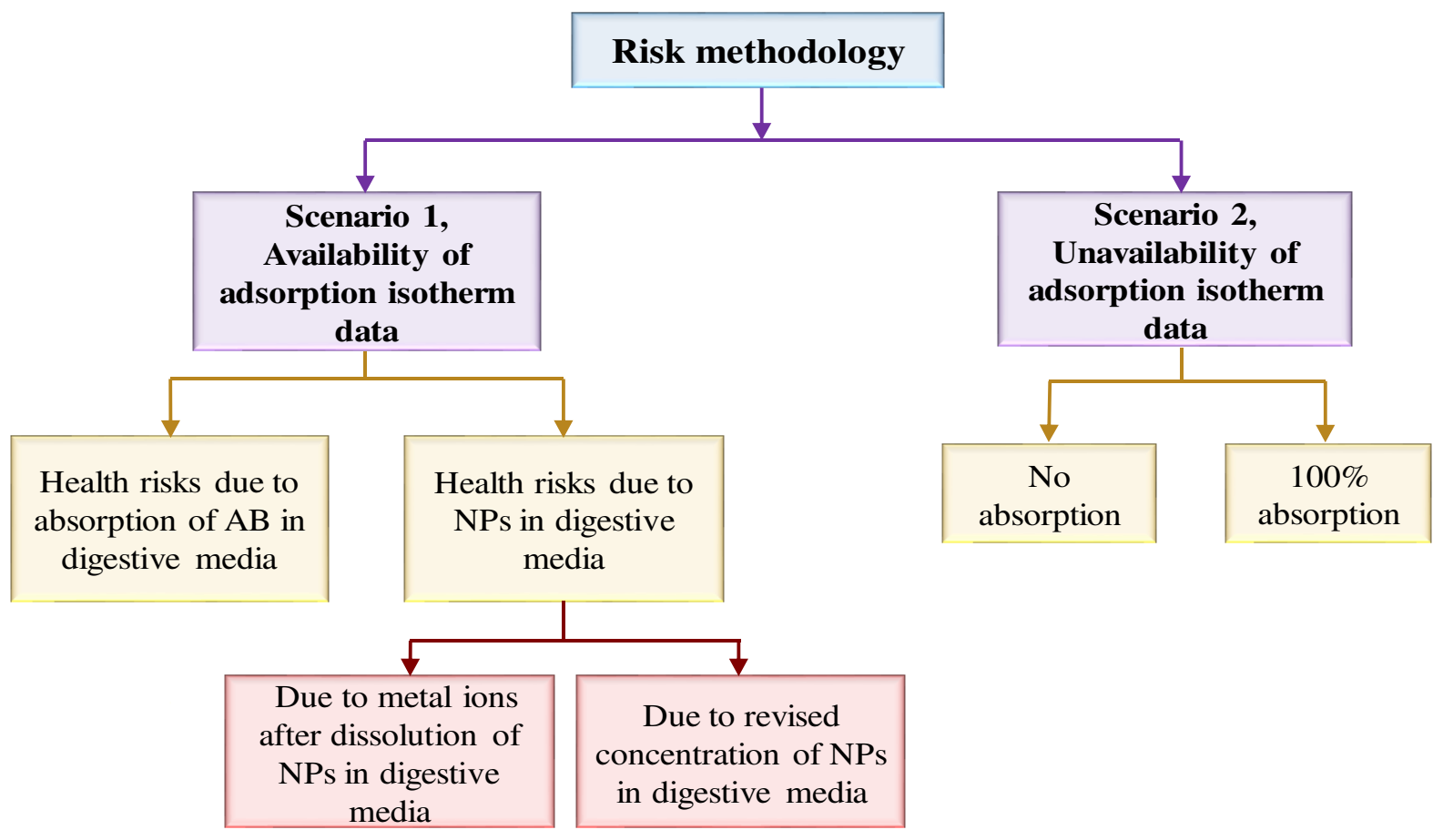

Fig. 1a Scenarios considered for determining risk exposure to humans

Under scenario 1, the study considered nanoparticles for which the adsorption isotherm data was available in literature. Scenario 2 indicates the condition where the adsorption isotherm data for the selected nanoparticles was not available in published literature. For scenario 1, risk was estimated for two different exposure routes (1) Risks due to absorption of antibiotics in the digestive media only, and (2) Risk due to absorption of 172 nanoparticles in digestive media. Under exposure route 2, two sub-routes were considered: (a) Route 2a: risk due to exposure to metal ions after the dissolution of nanoparticles in digestive liquid, (b) Route 2b: risk due to the revised concentration of nanoparticles in digestive media. For scenario 2, two cases (i) no absorption, and (ii) $100 \%$ absorption were considered. The detailed information is provided in the sections to follow. 
It is believed that oral ingestion serves as the main and primary route for the probable uptake of NPs to target sites or structures followed by their dissolution in the human digestive system (Fig. 1). In risk assessment, dissolution of NPs in the human digestive system gives a realistic and accurate quantity of nanoparticle loading to the digestive system. During risk estimation process, bio accessibility fraction of nanoparticles $\left(\mathrm{BAF}_{\mathrm{NP}}\right)$ was considered to show the influence of parameters governing the interaction of NPs with digestive liquid, and also to calculate the realistic exposure dose. $\mathrm{BAF}_{\mathrm{NP}}$ serves an important parameter as it considers the dissolution of nanoparticle to metals ions in the human digestive system. This study used the BAF values of nanoparticles available in literature for risk assessment purpose (Zhong et al., 2017). It is observed that the dissolution of nanoparticles led to the release of metal ions in the digestive system. Therefore, it is also important to determine exposure doses for the residual concentrations of released metal ions and nanoparticles in the digestive system to get the overall risk exposures of NPs absorption in the digestive media. media was carried out in terms of the average daily dose of metal ions ( $\mathrm{ADD}_{M i, D M}$ ) to the human digestive system using the $\mathrm{BAF}_{N P}$ as mentioned above. $\mathrm{ADD}_{M i, D M}(\mathrm{mg} / \mathrm{kg} / \mathrm{day})$ for individual metal ions in the digestive system was estimated using Eq. (1). Similarly, risk of revised concentration of NPs in the digestive media followed by GI-Tract absorption was calculated as $A D D_{R_{-} N P, D M}$. $A D_{R_{-} N P, D M}$ of individual NP was determined using Eq. (2).

200

201

$A D D_{M_{i}, D M}=\frac{C_{M i} \times B A F_{N P} \times I R_{w} \times E F \times E D}{B W \times A T}$ 
Where, $\mathrm{C}_{M i}$ is the concentration of released metal ions in the digestive media; $\mathrm{BAF}_{N P}$

is the bio-assimilation potential of NPs; $\mathrm{C}_{N P, D M}$ is the revised concentration of NPs in the human digestive system.

208

2.2.2 Risk estimation of ABs in the digestive media followed by oral administration when the isotherm data is available

In this case, concentration of nanoparticles was assumed to be $1 \mathrm{mg} / \mathrm{L}$. Concentration of $\mathrm{ABs}$ after adsorption by nanoparticles $(\mathrm{mg} / \mathrm{g})$ is taken from published literature, provided as supplementary information, Table S2. To determine the concentration of antibiotics in adsorbed form on nanoparticles in $\mathrm{mg} / \mathrm{L}$, the concentration of nanoparticles $(\mathrm{mg} / \mathrm{L})$ was multiplied by concentration of antibiotics after absorption on NPs (mg/g) and divided by 1000. 1000 is the conversion factor. To calculate the concentration of antibiotics in the human digestive media followed by GI-tract absorption (Conc $\mathrm{AB}_{-} \mathrm{DM}$ ) after oral ingestion, dissolution rate of antibiotics in the digestive media and the rate at which antibiotics is getting absorbed by the GI-tract is taken into account. Dissolution rate and absorption rate of data of antibiotics is taken from those reported in literature and is provided as supplementary Table S4. Conc $\mathrm{AB}_{-}$DM is calculated using Eq. (3). 
To determine the risk exposure effects, chronic daily intake (CDI) values (mg/kg-bw/day) were estimated using Eq. (4).

$C D I_{A B_{-} D M}=\frac{C_{A B_{-} D M} \times I R \times E T \times E D}{B W \times A T}$

Where, $\mathrm{C}_{A B_{-} D M}$ is the concentration of antibiotics in the digestive media followed by GI-tract absorption in GI-tract in $\mathrm{mg} / \mathrm{L}, \mathrm{BW}$ is the body weight $(\mathrm{Kg})$; IR is the intake rate of water, $\mathrm{EF}$ is exposure frequency (365 days/year), and ED is the exposure duration (70 Yrs.).

\subsubsection{Risks estimation when the adsorption isotherm data were not available}

This study also tried to determine risk exposure effects for human health for a hypothetical situation where the adsorption isotherm data of $\mathrm{ABs}$ on adsorption by nanoparticles is not available. Under this scenario, two different cases (i) no absorption, and (ii) 100\% absorption were considered to determine risk estimates.

(i) No absorption: Under this case, it is assumed that no absorption of NPs takes place in the GI-tract, and the ABs ingested remains as free $\mathrm{ABs}$ in the digestive media. Risk exposure of $\mathrm{ABs}$ was estimated using the surface water concentration of $\mathrm{ABs}$ as mentioned in the hazard identification section. Acceptable daily intake (ADI) values of individual antibiotics were used to calculate the Predicted no-effect concentration (PNEC) values. ADI values specifies the level of daily intake that should not result in any damaging effects to human health from direct exposure (Cunningham et al., 2009) whereas PNECs represent the lowest concentration values at which no harmful effects are anticipated. Input parameters used to estimate PNEC values and ADI values of the antibiotics is given in Table 1. PNEC values were estimated using Eq. (5) as given below. 
Where, ADI is Acceptable Daily Intake $\left(\mu \mathrm{g} \mathrm{kg-day}{ }^{-1}\right)$; BW is body weight of children in $\mathrm{Kg}$; $\mathrm{IR}_{w}$ is the intake rate of water in $\mathrm{L} \mathrm{day}^{-1}$; and $\mathrm{GI}_{A F}$ is the gastrointestinal absorption factor of antibiotics, assumed to be 1 in this study.

(ii) $100 \%$ absorption: Under this case, it is assumed that the amount of NPs and ABs is getting fully absorbed in the GI-tract. Risk was estimated similar to the approach mentioned in section 2.2.1.

\subsection{Dose-response assessment}

Limited available data on the reference doses (RfDs) of nanoparticles, for instance, $\mathrm{TiO}_{2}$ and $\mathrm{Fe}_{3} \mathrm{O}_{4}$ in the human digestive system makes it difficult to determine possible risks to human health. To fill this knowledge gap, this study used the recommended reference dose values of ions to denote the reference dose values of nanoparticles, where the RfD values of nanoparticles were considered equal to their corresponding ions. As mentioned earlier, since the RfD values for a majority of nanoparticles considered in this study is not available in the published literature hence, toxicity values of metal ions were used to represent the toxicity of NPs. A reference dose value for iron is neither available in the Integrated Risk Information System (IRIS) (U.S. EPA, 2006a) nor the Drinking Water Standards and Health Advisories list (U.S. EPA, 2005). Therefore, in this case, the provisional RfD (p-RfD) values for iron, derived using the lowest-observed-adverse-effect level (LOAEL) and uncertainty factor (UF) was considered (U.S. EPA, 2006b). RfD values of other nanoparticles i.e., $\mathrm{ZnO}$ NPs and $\mathrm{CuO}$ NPs is taken from recently published work (Parsai and Kumar, 2020). ADI values of individual antibiotics used to estimate the PNEC values is taken from published literature. Table 1 lists information about the parameters used for risk estimation. 
274 Table 1 Information about parameters used to determine risk estimates

\begin{tabular}{|c|c|c|c|}
\hline Parameters & Units & Values & References \\
\hline Body weight, BW & $\mathrm{Kg}$ & 16.7 & Argall et al., 2003 \\
\hline Average time, AT & Year & $365 \times 70$ & ATSDR, 2005 \\
\hline Exposure Duration, ED & Year & 70 & \\
\hline Exposure Frequency, ED & Days & 365 & \\
\hline \multicolumn{4}{|l|}{ Reference dose values, RfD } \\
\hline $\mathrm{ZnO} \mathrm{NPs}$ & $\mathrm{mg} \mathrm{kg}^{-1} \mathrm{day}^{-1}$ & 0.0315 & Parsai and Kumar, 2020 \\
\hline $\mathrm{CuO}$ NPs & $\mathrm{mg} \mathrm{kg}^{-1} \mathrm{day}^{-1}$ & 0.0262 & \\
\hline $\mathrm{TiO}_{2}$ NPs as $\mathrm{Ti}^{2+}$ ion & mg kg-bw ${ }^{-1}$ day $^{-1}$ & 3 & Ramoju et al., 2020 \\
\hline $\mathrm{Fe}_{3} \mathrm{O}_{4} \mathrm{NPs}$ as $\mathrm{Fe}^{3+}$ ion & mg kg-day & 0.7 & U.S. EPA, 2006b \\
\hline $\mathrm{Zn}^{2+}$ & $\mathrm{mg} \mathrm{kg}^{-1} \mathrm{day}^{-1}$ & 0.3 & IRIS, 2005 \\
\hline $\mathrm{Cu}^{2+}$ & $\mathrm{mg} \mathrm{kg}^{-1} \mathrm{day}^{-1}$ & 0.04 & \\
\hline
\end{tabular}

2.4 Risk estimation and characterization

Hazard quotient (HQ) values were calculated to determine risk to children. HQ is the ratio of 279 the possible exposure to a contaminant and the extent to which no adverse effects are expected to occur. If the HQ is observed to be less than 1, then no adverse health consequence is anticipated as a result of exposure (Kumari et al., 2015). HQ values were calculated using the CDI and ADD values estimated in the exposure assessment section and RfD values taken from table 1 as given in Eq. (6-9). Estimated HQ values were used the calculate the hazard index (HI) values for interactions of (i) antibiotics with metal ions, (ii) antibiotics with nanoparticles, and (iii) metal ions with nanoparticles in the human digestive 
system as mentioned ins Eq. (10-12). Limited information is available in published literature

287

288

289

290

291

292

293

294

295

296

297

298

299

300

301

302

303

304

305

306

307

308

309 on how antibiotics interact with metal ions or nanoparticles. Urbaniak et al. (2007) used ' $k$ ' values to provide information on the strength of interaction between fluoroquinolones and metals and observed strong interaction between them. Few studies reported synergistic effects for the interactions of antibiotics with nanoparticles (Abo-Shama et al., 2020) or metal ions (Nazari et al., 2012) however antagonistic effects do occur as well. Turel (2002) in his study showed that the activity of fluoroquinolones reduces in the presence of metal ions. Complexation with metal ions is one of the primary reason for the reduced activity of fluoroquinoloes (Seedher and Agarwal, 2010), and also modifies their solubility and binding capacity (Djurdjevic et al., 2007). This study assumed that synergistic effects occurs for the interaction of antibiotics with metal ions or nanoparticles. For case (i) and (ii), HI values were estimated using the modified USEPA Weight of Evidence (WoE) approach adopted from Kumari and Kumar (2020a) study. The detailed information and formula is provided as supplementary Text information, T1. Under WoE approach, $\mathrm{M}_{\mathrm{ij}}$ which indicates the magnitude of interaction i.e. the influence of $j^{\text {th }}$ compound on the toxicity of $i^{\text {th }}$ compound was taken as 5, the default value as per USEPA recommendations, and $\mathrm{B}_{\mathrm{ij}}$ denotes the strength of evidence for which scores were assigned as per the UEPA classification scheme (USEPA 2009a, b). For case (iii) i.e., HI values for the interaction of metal ions with NPs, it was assumed that they do not interfere with each other and therefore does not pose any toxic effects to human health. Dose-addition method was used to estimate HI values as mentioned in Eq. (12).

$H Q_{A B_{-} D M}=\frac{C D I_{A B_{-} D M}}{A D I}$

$H Q_{M i \_D M}=\frac{A D D_{M i \_D M}}{R f D_{M i}}$ 
$H Q_{R_{N P_{-} D} D M}=\frac{A D D_{R_{N P_{-} D} D}}{R f D}$

$311 \quad H Q=\frac{E C}{P N E C}$

312

$H I=H Q_{\text {antibiotics }}+H Q_{\text {metal ions }}$

313

$H I=H Q_{\text {antibiotics }}+H Q_{N P s}$

$H I=H Q_{\text {metal ions }}+H Q_{N P s}$

2.5 Risk management

317

Maximum allowable concentration $\left(\mathrm{C}_{\max }\right)$ can be defined as the concentration beyond which no adverse effects or risk exposure can occur. $\mathrm{C}_{\max }$ specifies the upper limit values of substance under study and can provide a helping hand to regulatory agencies for managing the risk. To calculate the $C_{\max }$ values, the HQ values in Eq. (6-9) was set as 1 , and the concentration was calculated.

\section{Result and discussion}

3.1 Estimation of nanoparticles and antibiotics loading in the digestive media

The results revealed that $\mathrm{Fe}_{3} \mathrm{O}_{4}$ NPs showed high bio-accumulation in the digestive system with a value of $2.58 \times 10^{-3} \mathrm{mg} / \mathrm{L}$. The comparative analysis indicated that $\mathrm{Fe}_{3} \mathrm{O}_{4} \mathrm{NPs}$ has the highest accumulation in the digestive media which was followed by $\mathrm{ZnO}$ NPs $\left(5.77 \times 10^{-8}\right.$ $\mathrm{mg} / \mathrm{L}), \mathrm{CuO} \mathrm{NPs}\left(2.40 \times 10^{-9} \mathrm{mg} / \mathrm{L}\right)$ and $\mathrm{TiO}_{2} \mathrm{NPs}\left(7.19 \times 10^{-10} \mathrm{mg} / \mathrm{L}\right)$. Overall, concentration of $\mathrm{Fe}_{3} \mathrm{O}_{4}$ NPs was found to be highest amongst all the nanoparticles considered for this study. High accumulation of nanoparticles like $\mathrm{ZnO}$ and $\mathrm{CuO}$ NPs in the digestive system can be related to their size. Larger the size of nanoparticles higher is the accumulation 
332 potential in the human digestive system (Bergin and Witzmann, 2013). The observed 333 sequence of nanoparticles in the human digestive system is similar to those observed by 334 Parsai and Kumar (2020).

Similar to nanoparticles, the concentration of antibiotics in the human digestive media $\left(\mathrm{C}_{\mathrm{AB} \_\mathrm{DM}}\right)$ after nanoparticles dissolution was also calculated to determine the accumulation 337 potential of antibiotics in the human digestive system. The concentration of levofloxacin cannot be determined due to the lack of adsorption isotherm data. Hence, as a result further risk assessment studies were not carried out although, it can be done only if the data is available. Amongst the antibiotics considered, ofloxacin $\left(1.8 \times 10^{-3} \mathrm{mg} / \mathrm{L}\right)$ showed highest accumulation potential in the human digestive system next to ciprofloxacin $\left(3.87 \times 10^{-7}\right.$ $\mathrm{mg} / \mathrm{L})$ and norfloxacin $\left(4.44 \times 10^{-7} \mathrm{mg} / \mathrm{L}\right)$. Wingender et al. (1985) in his study reported rapid absorption of ciprofloxacin in the upper GI-tract however comprehensive information on the absorption of ciprofloxacin or any other FQ in different parts of the human GI-tract does not exists (Harder et al., 1990). Furneri et al. (2000) suggested that accumulation of FQs antimicrobial agents is reduced by lowered $\mathrm{pH}$ and, under some conditions, by divalent cations as well.

3.2. Risk estimation

3.2.1 Risk estimation of NPs in the digestive media followed by GI-tract absorption when the isotherm data is available

3.2.1.1 Risk estimation of metal ions released in the digestive media after dissolution of nanoparticles 
The results revealed that the HQ values for all types of metals ions released in the human digestive system after nanoparticle dissolution were observed to be less than 1 under the conditions assumed in this study. This indicated that the metal ions released from the nanoparticles in the human digestive system does not show any significant health risks to human health [HQ values ranged from $1.44 \times 10^{-11}$ (for $\mathrm{Ti}^{2+}$ ions) to $2.21 \times 10^{-4}$ (for $\mathrm{Fe}^{3+}$ ions)]. HQ values more than 1 shows possible health concerns.

3.2.1.2 Estimation of risks due to the revised concentration of nanoparticles in the digestive media after dissolution of nanoparticles

HQ values calculated for the revised concentration of nanoparticles in the human digestive system were in the sequence of (low to high): $\mathrm{ZnO}$ NPs, $3.43 \times 10^{-8}$; $\mathrm{TiO}_{2} \mathrm{NPs}, 3.19 \times 10^{-7}$; $\mathrm{CuO}$ NPs, $2.28 \times 10^{-5} ; \mathrm{Fe}_{3} \mathrm{O}_{4}$ NPs, $2.85 \times 10^{-3}$ (Table 2). The results showed that the estimated HQ values for the revised concentration of nanoparticles were smaller than 1 , the acceptable risk level, indicating no significant risks to human health. Amongst the nanoparticles considered, $\mathrm{Fe}_{3} \mathrm{O}_{4}$ NPs showed comparatively high HQ values than other nanoparticles. It is important here to mention that till the time of writing no such studies (as per the author's best knowledge) has been reported in literature to determine risks for the released concentration of metal ions as well as nanoparticles in the human digestive system. It is also not known how the released metal ions behave after their dissolution from nanoparticles in the digestive media. Moreover, no guidelines or recommendations is available on the use of nanomaterials as a coating agent for drug delivery. In spite of being used in numerous biomedical and other industrial uses, the safety, toxicity, and its interaction with and within the biological systems are still unclear (Snyder-Talkington et al. 2012; Zhong et al., 2017). 
379 Table 2 Summary of the estimated risk of nanoparticles released in the digestive media

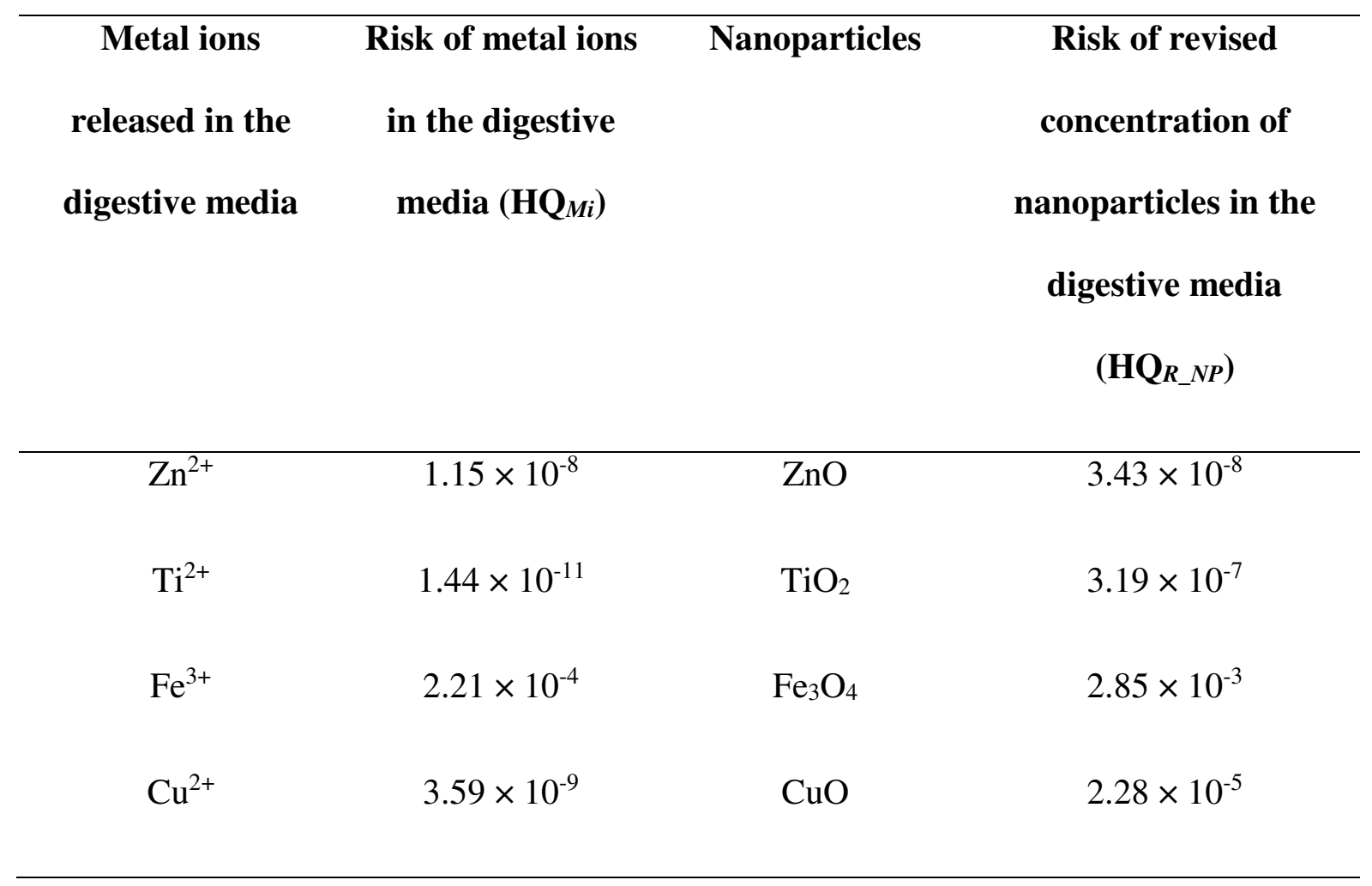

3.2.1.3. Risk of revised concentration of antibiotics in the digestive system after release from nanoparticles and absorption in GI-tract

HQ values estimated using the revised concentration of antibiotics in the human digestive system ranged from $1.90 \times 10^{-12}(\mathrm{NOR})$ to $3.37 \times 10^{-8}(\mathrm{OFX})$. The observed values indicate that no possible risks exist to human health as the obtained HQ values were less than the acceptable risk level. Amongst all, it was observed that CIP concentration may pose risks to human health due to low values. Overall, the results of risk evaluations disclosed that there exist no risks to human health for the consumption of nanoparticles coated antibiotics though oral ingestion of water under the conditions assumed in this study and for the scenario's considered. Although the estimated risk values were below the acceptable risk level but still 
the amount of nanoparticles to be used as a coating material for antibiotics needs to be regulated prior to its use for human.

\subsection{Risk estimation when the adsorption isotherm data is available}

\subsubsection{No absorption}

The term "No absorption" implies that under the hypothetical scenario considered no adsorption of antibiotics on nanoparticles takes place. As mentioned in the exposure assessment section, in this case, risk was estimated only for the oral ingestion of surface water contaminated with antibiotics. PNEC values were estimated to determine risk exposure effects. PNECs provides more accurate estimates and can be refined using detailed information considering different assessment factors (Bopp et al., 2019). The calculated PNEC values were observed to be (high to low): norfloxacin $(233.80 \mu \mathrm{g} / \mathrm{L})>$ ofloxacin $(53.44 \mu \mathrm{g} / \mathrm{L})>$ ciprofloxacin $(26.72 \mu \mathrm{g} / \mathrm{L})>$ levofloxacin $(2.505 \mu \mathrm{g} / \mathrm{L})$. HQ values ranged from $1.68 \times 10^{-3}$ (norfloxacin) to $4.3 \times 10^{-2}$ (levofloxacin) and are observed to less than the acceptable risk level (HQ < 1), therefore does not pose any significant risks to human health. An inverse relation was observed between PNEC and HQ values. Lower the PNEC values, higher the risk will be. Moreover, the PNEC values is directly dependent on the concentration of antibiotics in the environmental media. The results presented in this study is somehow similar to those reported by the authors (Kumari and Kumar, 2020a) in their previous work on sulfamethoxazole, ampillicin, and amoxicillin. Even though the presence of antibiotics in the water environment pose insignificant risks to human health, the risk management of these substances is required so as to protect human beings from their detrimental effects, if any. A thorough monitoring of these antibiotics in water bodies is required to protect the human health. 
417 The term "100\% absorption" implies that under the hypothetical scenario, it was assumed that 418 total adsorption of antibiotics by nanoparticles occurs. Figure 2 shows the HQ values of 419 individual antibiotics for different nanoparticles. As can been seen, the HQ values for all the 420 antibiotics were observed to be less than 1, the acceptable risk, indicating no significant risks 421 to human health. Amongst the NPs studied, high risk values were observed for ZnO NPs 422 compared to others. Similar to the other cases, here also, absorption of ZnO NPs in the 423 human digestive system was found to be the highest. Parsai and Kumar (2020) found high $424 \mathrm{HQ}$ values for $\mathrm{ZnO} \mathrm{NPs}$ thorough fish consumption exposure. The toxicity of $\mathrm{ZnO}$ nanoparticles might be due to their solubility. It is reported that dissolution of $\mathrm{ZnO}$ nanoparticles takes place in the extracellular region, which in turn increase the level of 427 intracellular $\mathrm{Zn}^{2+}$. However, the mechanism behind the increased level of intracellular $\mathrm{Zn}^{2+}$ 428 ions and dissolution of $\mathrm{ZnO}$ nanoparticles in the medium is still unclear (Pandurangan and 429 Kim, 2015).

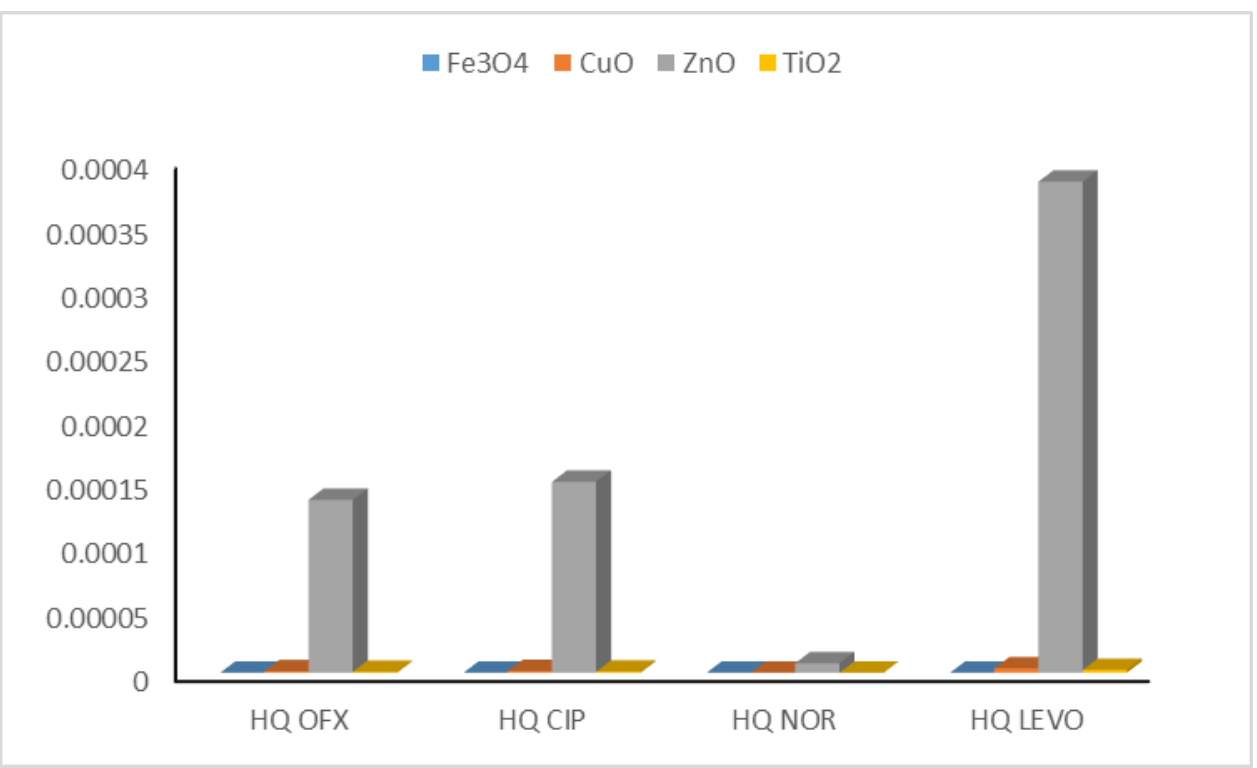


This study estimated risks due to the exposure of single type of nanoparticle at-a-time.

435 The chance assembly of more than one type of nanoparticles or antibiotics was not considered due to lack of information on the BAF values of mixture of NPs, dissolution and absorption rate of mixture of antibiotics in the GI-tract, dissolution of nanoparticles to their corresponding ions in the digestive system and RfD values. The present study showed an example of determining risk estimates in digestive system after including all the important parameters and highlighted its significance for human health. This type of risk assessment studies has not been conducted and this is the first time an attempt has been made to predict risk of contaminants within the human digestive system. The developed framework will help in assessing risk effects of the exposure of NP coated ABs to human in the digestive system. Though, few studies have estimated risks due the exposure of nanoparticles (Pizzol et al., 2019; Yang et al., 2017) and antibiotics (Kumari and Kumar, 2020a; 2020b) but none of them have considered the effect of human digestive media on the fate of nanoparticles and antibiotics including the reference dose values of NPs. The proposed framework included the effects of dissolution of nanoparticles to their corresponding ions in digestive system and estimated the revised concentration of antibiotics in the digestive media so as to provide more realistic values of both nanoparticles and antibiotics in the human digestive system. The suggested framework provides a step-wise approach to determine the risks exposure effects of NPs and ABs-complexes in the human digestive system. 
Under the conditions assumed in this study, the NPs coated ABs after oral ingestion undergoes absorption in the GI-tract and dissolved to produce different fractions as mentioned in the exposure assessment section, therefore, it is essential to calculate the risk of these released components in the human digestive system to provide more realistic risk estimates. For case (i) HI interaction of antibiotics with metal ions, the results revealed that the interactions of antibiotics with metal ions in the human digestive system does not pose any risks to human health as the estimated $\mathrm{HI}$ values were less than 1 ( $\mathrm{HI}_{\text {int }}$ for antibioticsmetal ion pairs $<1$ ) for all the conditions assumed in this study. In case (ii) HI interaction of antibiotics with nanoparticles, the calculated $\mathrm{HI}_{\text {int }}$ values were also observed to be less than 1 , the acceptable risk level and therefore, does not pose any risk to human health, if present together. For case (iii) HI interaction of antibiotics with metal ions, similar to the results obtained for the above two cases, here also the interaction results were smaller than 1 , indicating no significant health risks to human health. Overall, it was observed that no significant health was observed for the three mixture pairs as mentioned above. Although the HI interaction values were observed to be less than the acceptable risk level, still guideline values needs to be developed so as to regulate the amount and use of nanoparticles in targeted drug delivery systems as even a nano-gram increase in their concentrations might show adverse effects and can be detrimental to human health. Supplementary Table S5 shows information about the results obtained for all the cases and combinations mentioned above.

Table 3 provides the calculated maximum allowable concentration for antibiotics, metal ions, and nanoparticles. $\mathrm{C}_{\max }$ values of metal ions at which no risks occur ranged from (high to low) $6.68 \times 10^{5} \mathrm{mg} / \mathrm{L}$ (for $\mathrm{Ti}^{2+}$ ions) to $6.27 \mathrm{mg} / \mathrm{L}$ (for $\mathrm{Zn}^{2+}$ ions). The estimated $\mathrm{C}_{\max }$ values 
479 of nanoparticles at which no health risks effects were observed ranged from $0.658 \mathrm{mg} / \mathrm{L}$ 480 (ZnO NPs) to $6.68 \times 10^{5} \mathrm{mg} / \mathrm{L}\left(\mathrm{TiO}_{2} \mathrm{NPs}\right)$. Amongst the NPs studied, $\mathrm{ZnO}$ NPs showed highest risk, and therefore, the $\mathrm{C}_{\max }$ values for $\mathrm{ZnO}$ NPs was found to be lowest followed by $\mathrm{Fe}_{3} \mathrm{O}_{4}, \mathrm{CuO}$, and $\mathrm{TiO}_{2}$ NPs, respectively. If we compare the $\mathrm{C}_{\max }$ values of metal ions with that of nanoparticles, it can be seen that the $\mathrm{Zn}^{2+}$ ions $(0.658 \mathrm{mg} / \mathrm{L})$ showed comparatively high $\mathrm{C}_{\max }$ values than $\mathrm{ZnO}$ NPs $(6.27 \mathrm{mg} / \mathrm{L})$. Previous studies also reported high $\mathrm{C}_{\max }$ values for $\mathrm{ZnO}$ NPs in water bodies for the inadvertent ingestion of NPs through fish consumption exposure (Parsai and Kumar, 2020). Similar $\mathrm{C}_{\max }$ values for $\mathrm{Ti}^{2+}$ ions and $\mathrm{TiO}_{2} \mathrm{NPs}$, and $\mathrm{Fe}^{3+}$ ions and $\mathrm{Fe}_{3} \mathrm{O}_{4}$ NPs as can be seen from Table 3 is due to the use of similar RfD values for metal ions and NPs (due to unavailability of RfD values for these NPs) during risk estimation. Therefore, there is a need for conducting in vivo and in vitro studies for determining RfD of nanoparticles to get accurate risk estimates. The observed results demonstrated that stern actions and control measures must be taken to reduce the risk exposure effects of metal ions and nanoparticles.

The $\mathrm{C}_{\max }$ values of antibiotics were also calculated to determine their allowable concentration in water systems. The study observed that $\mathrm{C}_{\max }$ of antibiotics beyond which no risk effects can occur was observed to be $2.5 \mu \mathrm{g} / \mathrm{L}$ (for levofloxacin), $53.44 \mu \mathrm{g} / \mathrm{L}$ (for ofloxacin), $26.72 \mu \mathrm{g} / \mathrm{L}$ (for ciprofloxacin), and $233.80 \mu \mathrm{g} / \mathrm{L}$ (for norfloxacin). On the basis of $497 \mathrm{C}_{\max }$ values, it can be said that levofloxacin pose maximum risk to children whereas norfloxacin shows minimum risk. Different $\mathrm{C}_{\max }$ values of antibiotics have been reported by researchers (Lubasch et al., 2000; Owen et al., 1997) which might be related to the administered dose of antibiotics and age of the population considered. It was observed that an inverse relationship exists between the maximum allowable concentration and hazard quotient values i.e., the lower the $\mathrm{C}_{\max }$ values the higher the risk will be and vice versa. The results obtained in this study can be used by the regulatory bodies like USEPA, OECED and 
504

505

506

507

WHO for setting up the guidelines values for metal ions, nanoparticles, and antibiotics in water.

Table 3 Maximum allowable values $\left(\mathrm{C}_{\max }\right)$ of metal ions, nanoparticles and antibiotics assuming HI values as 1; lowest values are shown in bold text and are italicised

Metal ions (mg/L)

Maximum

$\mathrm{Zn}^{2+}, 6.27 \quad \mathrm{Cu}^{2+}, 2.23 \times 10^{3} \quad \mathrm{Fe}^{3+}, 4.79 \times 10^{1^{*}} \quad \mathrm{Ti}^{2+}, 6.68 \times 10^{5 \#}$

allowable

concentrations,

$\mathrm{C}_{\max }$

Nanoparticles (mg/L)

Maximum

$$
\mathrm{ZnO}, 0.658
$$

$\mathrm{CuO}, 1.46 \times 10^{3}$ $\mathrm{Fe}_{3} \mathrm{O}_{4}, 4.79 \times$

$\mathrm{TiO}_{2}, 6.68 \times 10^{5 \#}$

allowable

$10^{1 *}$

concentrations,

$\mathrm{C}_{\max }$

\section{Antibiotics ( $\mu \mathrm{g} / \mathrm{L})$}

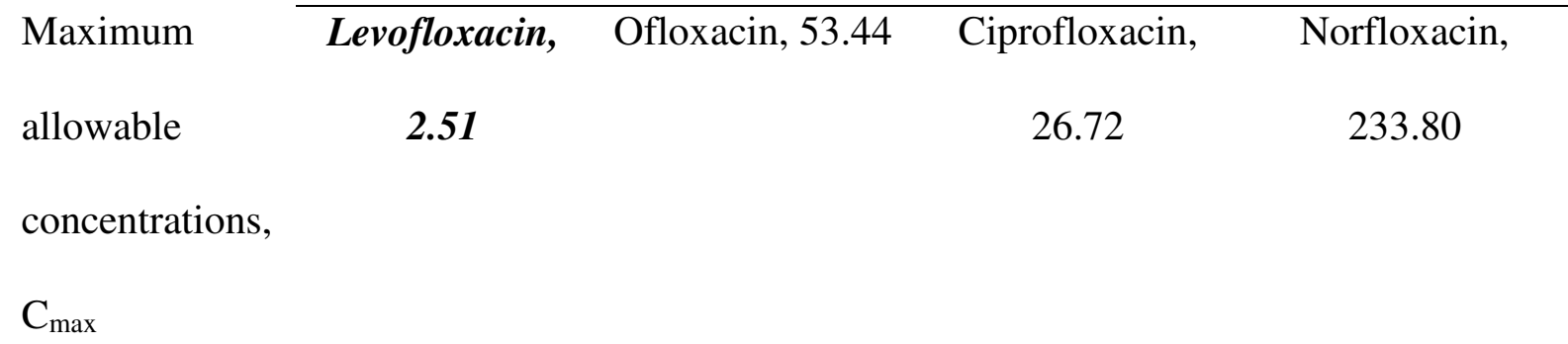


Due to lack of information on parameters used to determine risk estimates due to exposure of nanoparticles and antibiotics from natural waters, a lot of assumptions were made to fill the data gaps which includes (i) concentration of NPs: to calculate risk estimates of due to the interaction of nanoparticles with antibiotics, this study assumed the nanoparticle concentration to be $1 \mathrm{mg}$ (NPs) per $\mathrm{mg}$ of antibiotics (data taken from literature) to determine the concentration of antibiotics adsorbed on nanoparticles (mg/L). Under this assumption, it was observed that the estimated risk values for all the conditions studied does not pose any concerns to human health. However, risk estimates might vary as it directly depends on the concentration of substances used for the study (Kumari and Gupta, 2018) (ii) RfD values: Due to unavailability of reference dose values for nanoparticles considered in this study (as mentioned in the exposure assessment section), the RfD values of metal ions were taken (assuming that the values are equivalent and similar to that of nanoparticles) to estimate the risk values. At the assumed RfD values, no exists to human health for the conditions studied. The observed risk estimates might show different results, if estimated using accurate RfD values of nanoparticles (iii) BAF values: it determines the behavior of nanoparticles in solution. Transformation and actions of nanoparticles within the human digestive system is hard to anticipate (iv) ADI values of antibiotics: the values are taken from literature. Different values of the selected antibiotics have been reported by Wang et al. (2018) and Hanna et al. (2018) which creates a dilemma on which values to take for determining risk estimates, and thereby creating uncertainty in the overall process (v) $\mathrm{B}_{i j}$ values: The study assumed the $\mathrm{B}_{i j}$ values as 1 due to lack of information on the interaction of antibiotics with nanoparticles or metal ions. The risk estimates presented in this study indicate the point estimate values and can vary depending on variability of these parameters, creating uncertainty in risk estimates. Uncertainty analysis using Monte Carlo simulations needs to 534 performed to overcome these issues in risk estimates. Moreover, it is essential to recognize 
those parameters which adds high variability in HQ estimation so that efforts could be taken for reducing their variability in risk estimation process.

\section{Implications of the proposed framework}

This study proposed a framework using six-step risk assessment approach to determine the risk exposure effects of nanoparticles and antibiotics followed by oral ingestion and their possible interaction within the human digestive system. This study provides a systematic information on risk assessment involving the fate of nanoparticles and antibiotics within the human digestive system. Agencies like USEPA and FDA have suggested use of alternative testing strategies and data requirement for nanoparticles (Aschberger et al., 2016), however a systematic approach in dealing with nanoparticles and antibiotics does not exists. The proposed framework can be used by regulatory bodies such as USEPA, EU agencies and OECD for monitoring of nanoparticles and antibiotics in water. The outcome of the study will help in identifying the possible concentration of released compounds (antibiotics, nanoparticles, metal ions) in the human digestive system and the data generated can used for formulating guideline limits of both antibiotics and nanoparticles. Studies by Parsai and Kumar (2021) on nanoparticles and Kumari and Kumar (2020) has developed risk assessment framework for determining risk exposure effects alone and in mixture combination however none of the reported study analysed the interaction between these two contaminants. In this regard, this study will be helpful in understanding the interaction as well as the fate and behaviour two contaminants. Besides, the maximum allowable concentration values of contaminants derived in the study can be used by the regulatory bodies to regulate the concentration of antibiotics, nanoparticles and metal ions in natural water systems. 


\section{Summary and Conclusions}

560 The major findings of the study are presented below:

561

562

563

564

565

566

567

568

569

570

571

572

573

574

575

576

577

578

579

580

581

582

- The present study proposed a framework for assessing health risk exposure effects caused due to the interaction of nanoparticles and antibiotics followed by oral administration. The developed framework was applied to a hypothetical scenario where environmentally occurring concentration of nanoparticles $\left(\mathrm{Fe}_{3} \mathrm{O}_{4}, \mathrm{ZnO}, \mathrm{CuO}\right.$, and $\left.\mathrm{TiO} 2\right)$ and antibiotics (levofloxacin, ofloxacin, ciprofloxacin, norfloxacin) were taken for illustrative purpose.

- The study estimated the loading of antibiotics and nanoparticles in the human digestive system after their release. Amongst the nanoparticles, $\mathrm{Fe}_{3} \mathrm{O}_{4} \mathrm{NPs}\left(2.58 \times 10^{-3} \mathrm{mg} / \mathrm{L}\right)$ presented maximum accumulation in the digestive media whereas $\mathrm{TiO}_{2} \mathrm{NPs}$ the minimum $\left(7.19 \times 10^{-10} \mathrm{mg} / \mathrm{L}\right)$. Similarly, for antibiotics, ofloxacin has the highest accumulation rate in the human digestive system $\left(1.8 \times 10^{-3} \mathrm{mg} / \mathrm{L}\right)$.

- The risk estimated for two different scenarios showed hazard quotient values less than 1 under the conditions and assumptions made in this study. Therefore, on the basis of results obtained it can be said that the interaction of two contaminants does not pose any risks to human health followed by their release and dissolution in the human digestive system.

- Mixture toxicity (HI interactions) studies was conducted for three different binary combinations (i) antibiotics with metal ions, (ii) antibiotics with nanoparticles, and (iii) metal ions with nanoparticles. The estimated HI values for all the mixture combinations was observed to be less than 1, the acceptable limit, and therefore indicated no significant risks to human health. However, more detailed studies on the interactions antibiotics with metal ions and nanoparticles is required ( $\mathrm{B}_{i j}$ and $\mathrm{M} i j$ values in the WoE approach) for accurate risk predictions. 
- Overall, this work significantly increases our understanding on the fate of nanoparticles as well as antibiotics in the human digestive system and provides the knowledge base for better assessment of risk estimates of the studied contaminants in natural water systems. Efforts are required for conducting proper in vitro and in vivo eco-toxicity studies so that better understanding can be made on the fate and behaviour of released fragments of nanoparticles and antibiotics in the human digestive system.

\section{Data availability}

All the data supporting the results reported in the article are included in the manuscript and can be found in supplementary file. Data sharing is not applicable to this article as no datasets were generated or analyzed during the current study.

\section{Declarations}

Ethics approval and consent to participate: Not applicable

Consent for Publication: Both the authors have their consent for publishing the manuscript Availability of data and material: Not applicable

Competing interests: Not applicable

Funding: Not applicable

Authors' contributions: Minashree Kumari (Draft writing, analysis, Data interpretation, editing), Arun Kumar (Supervision, conceptualization and editing).

Acknowledgements: This research work was conducted by author Dr. Minashree Kumari as a part of her Institute Post-Doctoral Fellowship in the Department of Civil Engineering at Indian Institute of Technology, Delhi (IIT Delhi), India. The authors wish to acknowledge IIT Delhi for supporting this research. 
609

610

611

612

613

614

615

616

617

618

619

620

621

622

623

624

625

626

627

628

629

630

631

Abo-Shama, U.H., El-Gendy, H., Mousa, W.S., Hamouda, R.A., Yousuf, W.E., Hetta, H.F., Abdeen. (2020). Synergistics and antagonistic effect of metal nanoparticles in combination with antibiotics against some reference strains of pathogenic microorganisms. Infect Drug Resist., 13:351-362

Alder, A.C., McArdell, C.S., Golet, E.M., Ibric, S., Molnar, E., Nipales, N.S., Giger, W. (2001). Occurrence and fate of fluoroquinolone, macrolide, and sulfonamide antibiotics during wastewater treatment and in ambient waters in Switzerland. In: Daughton CG, Jones-Lepp TM (eds) Pharmaceuticals and Personal Care Products in the Environment: Scientific and Regulatory Issues. Symposium Series 791. American Chemical Society, Washington, DC, pp 56-69.

Argall, J.A.W., Wright, N., Mackway-Jones, K., Jackson, R. (2003). A comparison of two commonly used methods of weight estimation. Arch. Dis. Child. 88(9):789-790. doi:10.1136/adc.88.9.789.

Aschberger, K., Christensen, F.M., Rasmussen. K., Jensen, K.A. (2016). Feasibility and challenges of human health risk assessment for engineered nanomaterials. In: Engineered Nanoparticles and the Environment: Biophysicochemical Processes and Toxicity. pp. 409-441. doi:10.1002/9781119275855.ch21.

ATSDR (2005). Public Health Assessment Guidance Manual. Public Health Service Agency for Toxic Substances and Disease Registry Atlanta, Georgia, pp. 1-357 January.

Azizi, S., Mohamad, M., Abdul Rahim, R., Moghaddam, A.B., Moniri, M., Ariff, A., Saad, W.Z., Namvab, F. (2016) ZnO-Ag core-shell nanocomposite formed by green method using essential oil of wild ginger and their bactericidal and cytotoxic effects Appl. Surf. Sci. 384 517-24. 
632 Bergin, I.L., Witzmann, F.A (2013). Nanoparticle toxicity by the gastrointestinal route: 633 evidence and knowledge gaps. Int J Biomed Nanosci Nanotechnol., 3(1-2): 10.1504/IJBNN.2013.054515.

635

636

637

638

639

640

641

642

643

644

645

646

647

648

649

650

651

652

653

654

Bopp, S.K., Kienzler, A., Richarz, A-N., van der Linden, S.C., Paini, A., Parissis, N., Worth, A.P. (2019). Regulatory assessment and risk management of chemical mixtures: $\begin{array}{lllll}\text { challenges and } & \text { ways }\end{array}$ doi.org/10.1080/10408444.2019.1579169.

Canesi, L., Ciacci, C., Balbi, T., 2015. Interactive effects of nanoparticles with other contaminants in aquatic organisms: friend or foe? Mar. Environ. Res. 111, 128-134.

Chen, X., O'Halloran, J., Jansen, M.A.K. (2016). The toxicity of zinc oxide NPs to Lemna minor (L.) is predominantly caused by dissolved Zn. Aquat Toxicol 174:46-53. https ://doi.org/10.1016/j.aquat ox.2016.02.012.

Choma, I.M. (2003). TLC separation of fluoroquinolones: searching for better selectivity. J Liquid Chromatogr Relat Technol 26:2673-2685.

Coll, C., Notter, D., Gottschalk, F., Sun, T., Som, C., Nowack, B. (2016). Probabilistic environmental risk assessment of five nanomaterials (nano- $\mathrm{TiO} 2$, nano- $\mathrm{Ag}$, nano- $\mathrm{ZnO}$, CNT, and fullerenes). Nanotoxicology, 10(4), 436-444.

Croteau., M.N., Misra, S.K., Luoma, S.N., Valsami-Jones, E. (2014). Bioaccumulation and toxicity of $\mathrm{CuO}$ nanoparticles by a freshwater invertebrate after waterborne and dietborne exposures. Environ. Sci. Technol. 48(18):10929-10937. doi:10.1021/es5018703.

Cunningham, V.L., Binks, S.P., Olson, M.J. (2009). Human health risk assessment from the presence of human pharmaceuticals in the aquatic environment. Regul. Toxicol. Pharm. $53: 39-45$ 
Ding, W., Guo, L. (2013). Immobilized transferrin $\mathrm{Fe}_{3} \mathrm{O}_{4} @ \mathrm{SiO}_{2}$ nanoparticle with high doxorubicin loading for dual-targeted tumor drug delivery. International Journal of Nanomedicine, 8:4631-4639.

Djurdjevic, P., Joksovic, L., Jelic, R., Djurdjevic, A., Stankov, M.J. (2007). Solution equilibria between aluminium (III) ion and some fluoroquinolone family members. Spectroscopic and potentiometric study. Chem Pharm Bull, 55:1689-99.

Ebele, A.J., Abdallah, M, A-E., Harrad, S. (2017). Pharmaceuticals and personal care products (PPCPs) in the freshwater aquatic environment. Emerging Contaminants, 3(1), $1-16$.

Evangelou, M.W., Ebel, M., Schaeffer, A. (2007). Chelate assisted phytoextraction of heavy metals from soil. Effect, mechanism, toxicity, and fate of chelating agents. Chemosphere 68:989-1003. https://doi.org/10.1016/j.chemosphere.2007.01.062.

Furneri, M.P., Fresta, M., Puglisi, G., Tempera, G. (2000). Ofloxacin-Loaded Liposomes: In Vitro Activity and Drug Accumulation in Bacteria. Antimicrobials agents and chemotherapy, 2458-2464.

Hanna, N., Sun, P., Sun, Q., Li, X., Yang, X., Ji, X., Zou, H., Ottoson, J., Nilsson, L.E., Berglund, B., Dyar, O.J., Tamhankar, A.J., Lundborg, C.S. (2018). Presence of antibiotic residues in various environmental compartments of Shandong province in eastern China: Its potential for resistance development and ecological and human risk. Environ Int., $114: 131-142$.

Harder, S., Fuhr, U., Beermann, D., Staib, A.H. (1990). Ciprofloxacin absorption in different regions of the human gastrointestinal tract. Investigations with the hf-capsule. Br. J. clin. Pharmac., 30, 35-39.

Hartmann, N.B., Baun, A. (2010). The nano cocktail: ecotoxicological effects of engineered nanoparticles in chemical mixtures. Integr. Environ. Assess. Manag. 6, 311-313. 
Holden, P.A., Klaessig, F., Turco, R.F., Priester, J., Rico, C.M., Arias, H.A., Mortimer, M., Pacpaco, K., Gardea-Torresdey, J.L. (2014). Evaluation of Exposure Concentrations Used in Assessing Manufactured Nanomaterial Environmental Hazards: Are They Relevant? Environ. Sci. Technol., DOI: 10.1021/es502440s.

Hooper, D.C. \& Rubinstein, E. Quinolone antimicrobial agents. (ASM Press, Washington, D.C, 2003).

Hooper, D.C., Wolfson, J.S. (1993). Mechanism of quinolone action and bacterial killing. In: Hooper DC, Wolfson JS (eds) Quinolone Antibacterial Agents, 2nd Ed. American Society for Microbiology, Washington DC, pp 53-75.

IRIS (2005). Zinc and Compounds (CASRN 7440-66-6). U.S. Environmental Protection Agency, pp. 1-21. http://www.epa.gov/ iris/subst/0426.htm.

Kumar, A., Kumar, P., Anandan, A., Fernandes, T.F., Ayoko, G.A., Biskos, G. (2014). Engineered nanomaterials: knowledge gaps in fate, exposure, toxicity, and future directions. J. Nanomater. 2014.

Kumari, M., Kumar, A. (2020a). Human health risk assessment of antibiotics in binary

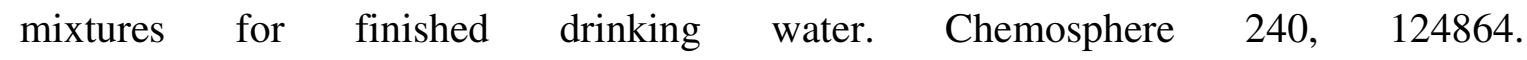
doi:10.1016/j.chemosphere.2019.124864.

Kumari, Minashree., Kumar, A. (2020b). Identification of component-based approach for prediction of joint chemical mixture toxicity risk assessment with respect to human health: A critical review. Food Chem. Toxicol., 111458.

Kumari, M., Gupta, S.K. (2018). Age dependent adjustment factor (ADAF) for the estimation of cancer risk through trihalomethanes (THMs) for different age groups- A innovative approach. Ecotox Environ Saf., 148, 960-968. 
703

704

705

706

707

708

709

710

711

712

713

714

715

716

717

718

719

720

721

722

723

724

725

726

Kumari, M., Gupta, S.K., \& Mishra, B.K. (2015). Multi-exposure cancer and non-cancer risk assessment of trihalomethanes in drinking water supplies - A case study of Eastern region of India. Ecotox Environ Saf., 113, 433-438.

Kurlanda-Witek, H., Ngwenya, B.T., Butler, I.B. (2014). Transport of bare and capped zinc oxide nanoparticles is dependent on porous medium composition. J Contam Hydrol 162163:17-26. https://doi.org/10.1016/j.jconhyd.2014.04.002.

Lammel, T., Wassmur, B., Mackevica, A., L.Chen, Chang-Er., Sturve, J. (2019). Mixture toxicity effects and uptake of titanium dioxide $\left(\mathrm{TiO}_{2}\right)$ nanoparticles and 3,3',4,4'tetrachlorobiphenyl (PCB77) in juvenile brown trout following co-exposure via the diet. Aquatic Toxicology, 213, 105195.

Li, J., Song, Y., Vogt, R.D., Liu, Y., Luo, J., Li, T. (2020). Bioavailability and cytotoxicity of cerium-(IV), copper-(II), and zinc oxide nanoparticles to human intestinal and liver cells through food. Sci. Total Environ. 702. doi:10.1016/j.scitotenv.2019.134700.

Lubasch, A., Keller, I., Borner, K., Koeppe, P., Lode, H. (2000) Comparative Pharmacokinetics of Ciprofloxacin, Gatifloxacin, Grepafloxacin, Levofloxacin, Trovafloxacin, and Moxifloxacin after Single Oral Administration in Healthy Volunteers. Antimicrob agents chemother., 2600-2603.

Menard, A., Drobne, D., Jemec, A. (2011). Ecotoxicity of nanosized $\mathrm{TiO}_{2}$. Review of in vivo data. Environ. Pollut. 159, 677-684.

MacGowan, A.P., Andersson, M.I. (2003). Development of the quinolones. J Antimicrob Chemother. 51:(Suppl 1):1-11.

Naasz, S., Altenburger, R., Kühnel, D. (2018). Environmental mixtures of nanomaterials and chemicals: The Trojan-horse phenomenon and its relevance for ecotoxicity. Science of The Total Environment, 635, 1:1170-1181. 
Namvar, F., Rahman, H. S., Mohamad, R., Baharara, J., Mahdavi, M., Amini, E. Yeap, S. K. (2014). Cytotoxic effect of magnetic iron oxide nanoparticles synthesized via seaweed aqueous extract. Int J Nanomedicine, 9:2479-2488. https://doi.org/10.2147/IJN.S59661.

Nazari, Z., Banoee, M., Sepahi, A.K., Rafii, F., Shahverdi. (2012). The combination effects of trivalent gold ions and gold nanoparticles with different antibiotics against resistant Pseudomonas aeruginosa. Gold. Bull., 45:53, doi:10.1007/s13404-012-0048-7.

Owens Jr. R.C., Patel, K.B., Banevicius, M.A., Quintiliani, R., Nightingale, C.H., Nicolau, D.P. (2007). Oral Bioavailability and Pharmacokinetics of Ciprofloxacin in Patients with AIDS. Antimicrob agents chemother., 1508-1511. doi.org/10.1128/AAC.41.7.1508.

Pandurangan, M., Kim, D.H. (2015). In vitro toxicity of zinc oxide nanoparticles: a review. J Nanopart Res 17: Artn 158. https://doi.org/10.1007/S11051-015-2958-9.

Parsai, T., Kumar, A. (2020). Tradeoff between risks through ingestion of nanoparticle contaminated water or fish: human health perspective. Sci. Total Environ., 140140.

Pizzol, L., Hristozov, D., Zabeo, A., Basei, G., Wohlleben, W., Koivisto, A.J., Jensen, K.A., Fransman, W., Stone, V., Marcomini, A. (2019). SUNDS probabilistic human health risk assessment methodology and its application to organic pigment used in the automotive industry. NanoImpact 13:26-36. doi:10.1016/j.impact.2018.12.001.

Ramoju, S., Andersen, M.E., Nong, A., Karyakina, N., Shilnikova, N., Krishnan, K., Krewski, D. (2020). Derivation of whole blood biomonitoring equivalents for titanium for the interpretation of biomonitoring data. Regul. Toxic Pharmacol., 114:104671.

Seedher, N., Agarwal, P. (2010). Effect of metal ions on some pharmacologically relevant interactions involving fluoroquinolone antibiotics. Drug Metab Drug Interact., 25(14):17-24. DOI 10.1515/DMDI.2010.003. 
Snyder-Talkington, N., Qian, Y., Castranova, V., Guo, N.L. (2012). New perspectives for in vitro risk assessment of multiwalled carbon nanotubes: application of co-culture and bioinformatics. J Toxicol Environ Health B 15:468-492.

Sukul, P and S. Michael (2007). Fluoroquinolone Antibiotics in the Environment. Rev Environ Contam Toxicol., 191:131-162.

Twining, J., McGlinn, P., Loi, E., Smith, K., Giere, R. (2005). Risk ranking of bioaccessible metals from fly ash dissolved in simulated lung and gut fluids. Environ Sci Technol 39:7749-7756. https://doi.org/10.1021/es0502369.

Urbaniak, B., Mrestani, Y., Kokot, Z.K., Neubert, R.H. (2007). Investigation of interaction of fluoroquinolones with aluminium, iron and magnesium ions using capillary zone electrophoresis. Chromatographia, 65:489-92.

US EPA (Environmental Protection Agency) (2005). Drinking Water Standards and Health Advisories. Office of Water, Washington, DC. Available at http://www.epa.gov/ost/drinking/standards/dwstandards.pdf.

US EPA (Environmental Protection Agency) (2006a). Integrated Risk Information System (IRIS). Online. Office of Research and Development. National Center for Environmental Assessment, Washington, D.C. www.epa.gov/iris.

US EPA (Environmental Protection Agency) (2006b). Provisional Peer Reviewed Toxicity Values for Iron and Compounds (CASRN 7439-89-6). Derivation of Subchronic and Chronic Oral RfDs.

Uwizeyimana, H., Wang, M., Chen, W., Khan, K. (2017). The eco-toxic effects of pesticide and heavy metal mixtures towards earthworms in soil. Environmental Toxicology and Pharmacology http://dx.doi.org/10.1016/j.etap.2017.08.001. 
Wang, X.H., Qu, R.J., Liu, J.Q.,Wei, Z.B.,Wang, L.S., Yang, S.G., et al. (2016). Effect of different carbon nanotubes on cadmium toxicity to Daphnia magna: the role of catalyst impurities and adsorption capacity. Environ. Pollut. 208, 732-738.

Wang, H., Tang, C., Yang, J., Wang, Na., Jiang, F., Xia, Q., He, G., Chen, Y., Jiang, Q. (2018). Predictors of urinary antibiotics in children of Shanghai and health risk assessment. Environ Int 121:507-514.

Wingender, W., Forster, D., Beermann, D., Rohwedder, R., Graefe, K. H. \& Schacht, P. (1985). Effect of gastric emptying time on rate and extent of the systemic availability of ciprofloxacin in humans. In Recent Advances in Chemotherapy, Antimicrobial section, ed. Ishigami, J., pp. 1585- 1586. University of Tokyo Press.

Yang, J., Cao, W., Rui, Y. (2017). Interactions between nanoparticles and plants: Phytotoxicity and defense mechanisms. J. Plant. Interact., 12, 158-169.

Ye, N., Wang, Z., Wang, Se., Fang, H., Wang, D. (2018). Dissolved organic matter and aluminum oxide nanoparticles synergistically cause cellular responses in freshwater microalgae. J. Environ. Sci. Health 53, 651-658.

Zhong, L., Yu, Y., Lian, H-z., Hu, X., Fu, H., Chen, Yi-j (2017). Solubility of nano-sized metal oxides evaluated by using in vitro simulated lung and gastrointestinal fluids: implication for health risks. J. Nanopart. Res. 19 (11). doi:10.1007/s11051-017-4064-7.

Zhu, X.S., Zhou, J., Cai, Z.H. (2011). $\mathrm{TiO}_{2}$ nanoparticles in the marine environment: impact on the toxicity of tributyltin to abalone (Haliotis diversicolor supertexta) embryos. Environ. Sci. Technol. 45, 3753-3758. 


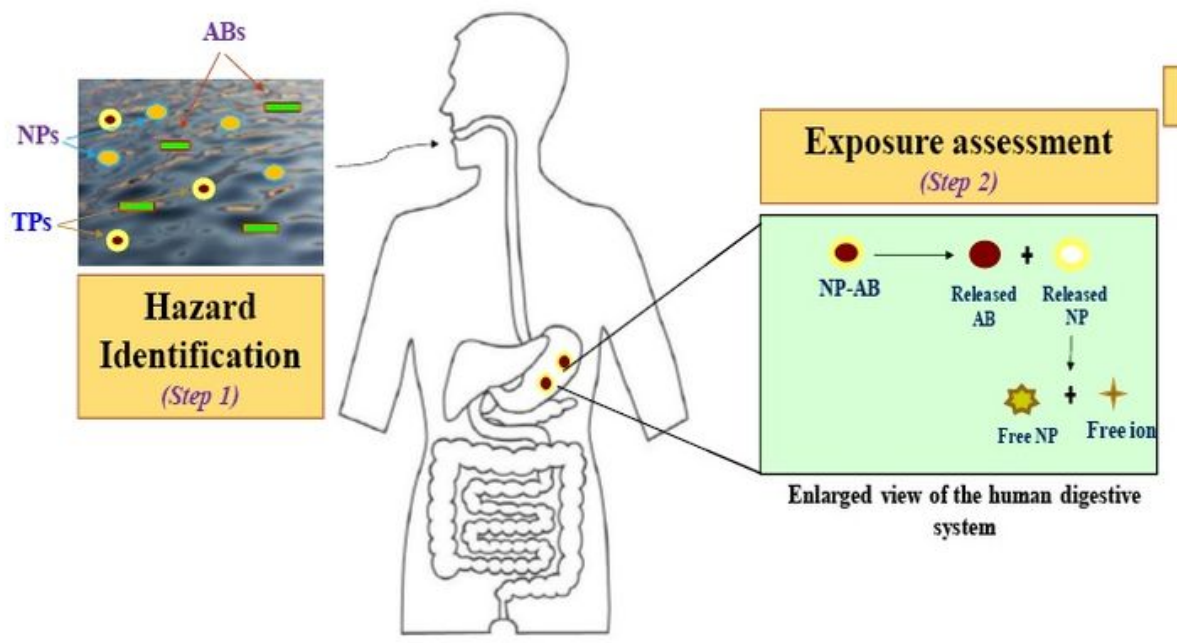

Dose-response (Step 3)

RfD for Nanoparticles

ADI for Antibiotics

Risk Estimation (Step 4)

$\mathrm{HQ}=\mathrm{ADD} / \mathrm{RfD}$,

Nanoparticles

$\mathrm{HQ}=\mathrm{EC} / \mathrm{PNEC}$ for

Antibiotics

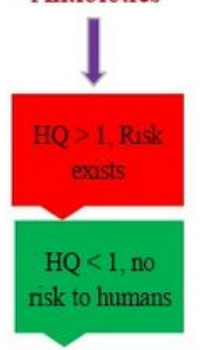

Fig. 1

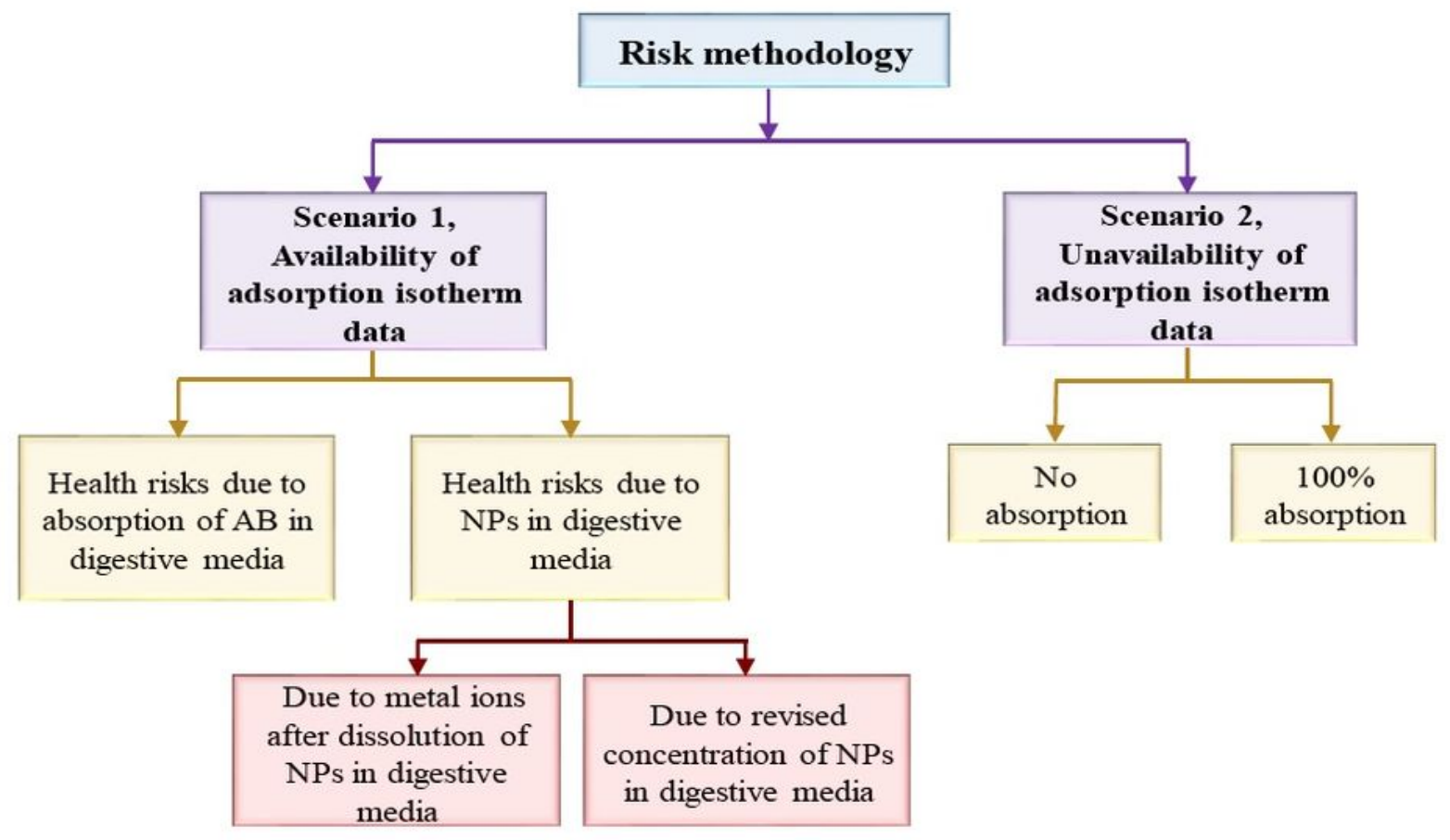

Fig. 1a

\section{Figure 1}

Hypothetical schematic diagram showing the uptake of nanoparticles-antibiotics transformed products and their dissolution in the human digestive system (NPS = nanoparticles, ABs = antibiotics, TPS = transformed products, $\mathrm{HQ}=$ hazard quotient, $\mathrm{EC}=$ Environmental concentration, $\mathrm{PNEC}=$ Predicted no- 
effect concentration; $\mathrm{RfD}=$ Reference dose; $\mathrm{ADI}$ = Acceptable daily intake). $1 \mathrm{a}$ Scenarios considered for determining risk exposure to humans

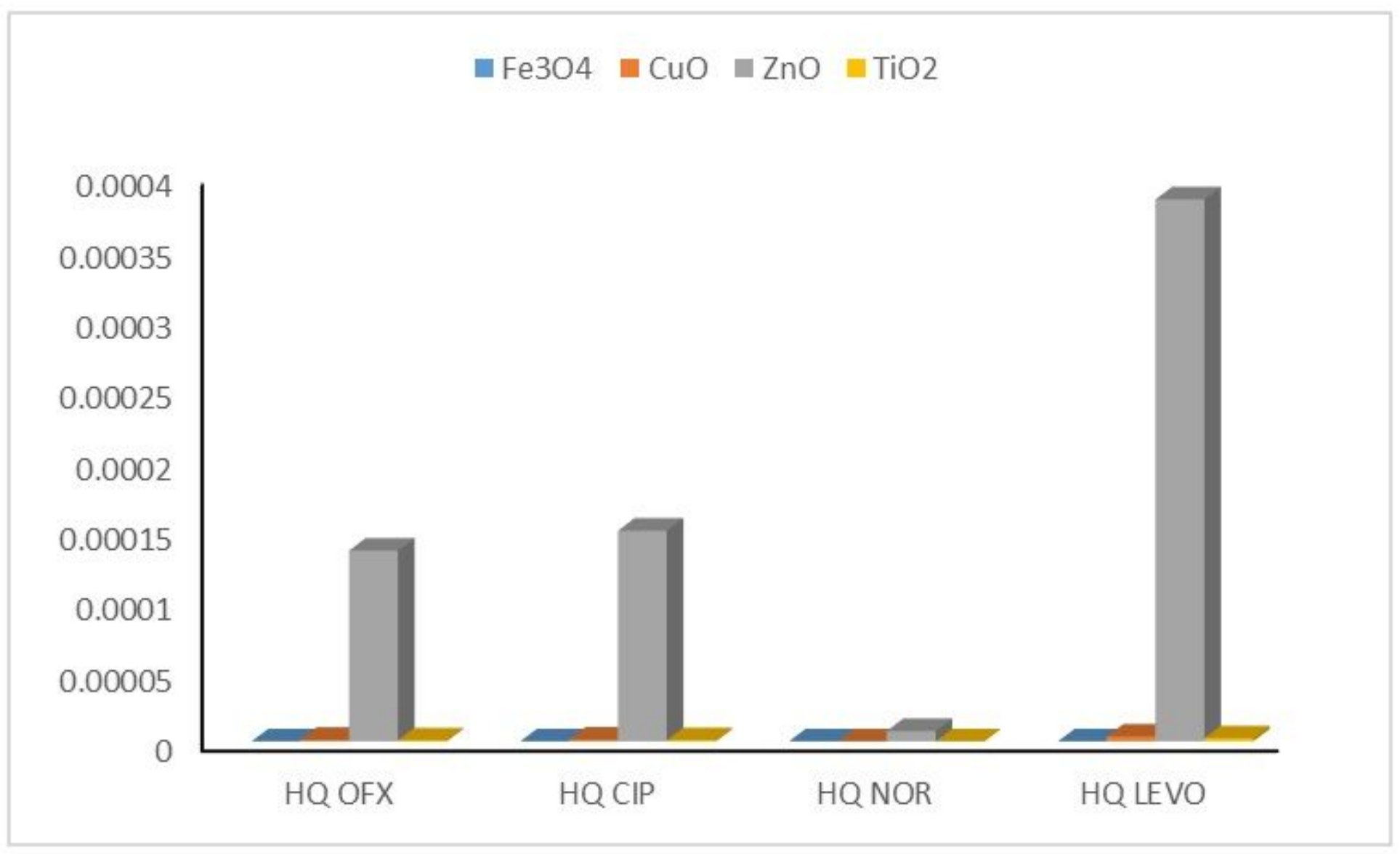

Figure 2

$\mathrm{HQ}$ values of nanoparticles for nanoparticles

\section{Supplementary Files}

This is a list of supplementary files associated with this preprint. Click to download.

- Supplementarymaterial.doc 